\title{
Age Distribution of a Zero-Growth Population: Implications for China
}

\author{
Song Jian ${ }^{1,2}$ \\ ${ }^{1}$ Chinese Academy of Engineering, Beijing, China \\ ${ }^{2}$ Chinese Academy of Sciences, Beijing, China \\ Email: songj@cae.cn
}

Received December $2^{\text {nd }}, 2012$; revised February $17^{\text {th }}, 2013$; accepted March $7^{\text {th }}, 2013$

\begin{abstract}
Copyright (C) 2013 Song Jian. This is an open access article distributed under the Creative Commons Attribution License, which permits unrestricted use, distribution, and reproduction in any medium, provided the original work is properly cited.
\end{abstract}

\begin{abstract}
It is generally accepted that zero-growth population would be the long-term destiny of any population. China's population is expected to reach 1.4 billion with zero-growth around 2030, if the low fertility policy continues up to then. Demographic dynamics indicate that the age composition of a steady zerogrowth society would asymptotically approach the population mix of today's many developed countries. Here we present a brief analysis and some insights into the age composition of a zero-growth society and the connectedness between total fertility rate, net reproduction rate and replacement level of fertility. Other formulas useful for demographic studies are also provided to further the analysis. Our results reveal that the age composition of China's population in 2050 would be similar to those of some developed countries today. We argue that the misgivings about "population aging" or the fear of a "winter of humanity" in China stem from rather oversimplified estimations.
\end{abstract}

Keywords: Age Composition; Zero-Growth Population; Total Fertility; Replacement Level; Population Aging; China

\section{Introduction}

It is self-evident that, given the size of the Earth's surface and its limited resources, the number of human population that the Earth or a country can support cannot be infinite. In 2011, the world population reached 7.0 billion, with an annual growth rate of $1.2 \%$ since 2000 . It is projected that the world's total population is likely to exceed 9.3 billion by the middle of the century (United Nations Population Division, 2011). Mainland China (hereafter China) has now 15.2 million newborns every year, a net growth of 5.03 million and a natural growth rate of 0.445 percent in 2011. Under the medium scenario (i.e., total fertility rate ranges from $1.5-1.8$ in the projection period), China's population would reach as high as 1.48 billion by the middle of the century. In the context of scarcity in land and water, even one per thousand annual growth is likely to be unsustainable in the long run.

There is a consensus that China has witnessed the demographic transition and achieved a noticeable economic growth within three decades (Hussain, 2002). The success of family planning program has contributed the lion's share to this development ( $\mathrm{Li}, 2009)$. According to the United Nations Population Division (UNPD) (2011), China's total fertility rate has dropped from 5.0 in 1970 to around $1.5-1.7$ at present, which is below the replacement level of fertility for 15 consecutive years. It is projected that China's population will be stabilized at 1.4 billion in the years of 2025-2030 if the current fertility rate follows its predicted trajectory from a Bayesian Hierarchical Model that captures the world's fertility evolution trajectory and China's own historical trend (Raftery et al., 2012; UNPD, 2011). From a long-term perspective, most countries in the world will have to achieve zero population growth eventually.

However, lowering total fertility rate, extending life expectancy at birth, and heightening the median age of a population would all imply inevitably the increase of the percentage of the elderly population. This is what some Chinese scholars have been concerned about recently. They began talking about "population aging", "senior boom" and even fears of a "winter of humanity" (e.g., Wang, 2005; Zou \& Yang, 2009).

The aims of this paper are: 1) to derive the demographic indicators, including age distribution, of a zero-growth population from population dynamics; and 2) to compare the age distribution of China's population in 2050 with that of a zero-growth population given the similar life expectancy.

\section{Demographic Dynamics}

Stationary population, aka zero growth population, has long been extensively discussed in research literature and many textbooks (e.g., Keyfitz, 1973; Preston, Heuveline, \& Guillot, 2001; Ryder, 1975). Because a life table or model life table population is a stationary population, previous studies, in most cases, rarely linked it with a real population when they were addressing the age structure of a stationary population, for no real population was (or close to) a stationary population thirty or forty years ago. Instead, they used the distribution in a life table or model life table at a given mortality level. This is justifiable and acceptable, although age distribution of a real popu- 
lation differs greatly from the life table or model life table. With life expectancy at birth in the more developed world reaching or exceeding age 80 , populations in many developed countries have now demonstrated some similar characteristics of a stationary population. This development improves our knowledge and enables us to better understand the age distribution of a currently non-stationary population in the future when it approaches a stationary population. Below I will provide some basic mathematical formulas that are important in determining the age structure of a stationary population.

Let $N(t)$ be the population size in the census year $t$ and $N_{i}(t)$ be the population aged $i$ but less than $I+1$ ( $i$ can be a single-year age group or a five-year age group), $I=0,1, \cdots, z$, with $z$ being the highest age to which one can live; $M(t)$ and $M_{i}(t)$ be the number of annual total deaths at age $i$ in year $t ; m(t)=$ $\frac{M(t)}{N(t)}$ and $m_{i}(t)=\frac{M_{i}(t)}{N_{i}(t)}$ be crude mortality rate and agespecific mortality rate in year $t ; B$ be the number of total live births in year $t$; and $b(t)=\frac{B(t)}{N(t)}$ be the crude birth rate in year $t$.

Assume that the total newborns in year $t$ is $B(t)$, and imagine that they go through their lives at the same age-specific mortality $\left\{m_{i}(t), I=0,1, \cdots z\right\}$ of the year. There are $m_{0}(t) N_{0}(t)=$ $\frac{M_{0}(t)}{N_{0}(t)} N_{0}(t)=M_{0}(t)$ infants who would die in the first year, $\left(1-m_{0}(t)\right) N_{0}(t)$ survive the first year and enter age one. Proceeding in this way, $m_{i}(t) N_{i}(t)$ would be the number of deaths at age $i$, and $\left(1-m_{i}(t)\right) N_{i}(t)$ would be number of survivors who enter the next age $I+1$ a year later. Assuming that $Q_{i}(t)$ is the net migrants of entering and leaving age $i$, we get a system of discrete equations of population dynamics from year $t$ to year $t$ +1 :

$$
\begin{aligned}
& N_{i+1}(t+1)=\left(1-m_{i}(t)\right) N_{i}(t)+Q_{i}(t), \\
& N_{1}(t+1)=\left(1-m_{0}(t)\right) N_{0}(t), N_{0}(t)=B(t), \\
& i=1,2, \cdots z ; t=0,1, \cdots
\end{aligned}
$$

Now assume $E_{i}(t)$ is the remaining life expectancy at age $i$ for all the members of $N_{i}(t)$ in year $t$. By definition, the sum of total years survived by all members of $N_{i}(t)$ is $E_{i}(t) N_{i}(t)$. If migration is not accounted for, from Equation (1) we get

$$
\begin{aligned}
& E_{i}(t) N_{i}(t)=\left(1-m_{i}(t)\right) N_{i}(t)+\left(1-m_{i+1}(t)\right) N_{i+1}(t) \\
& +\cdots+\left(1-m_{z-1}(t)\right) N_{z-1}(t) . \\
& =\left(1-m_{i}(t)\right) N_{i}(t)+\left(1-m_{i+1}(t)\right) \\
& \cdot\left(1-m_{i}(t-1)\right) N_{i}(t-1)+\ldots+\left(1-m_{z-1}(t)\right) \\
& \cdot\left(1-m_{i}(t-z+1)\right)\left(1-m_{i+1}(t-z+2)\right) \cdots \\
& \cdot\left(1-m_{z-2}(t-1)\right) N_{i}(t-z+1)
\end{aligned}
$$

Now we assume that in a steady zero-growth society $m_{i}(t) \equiv$ $m_{i}(t+1)$ and $B(t) \equiv B(t+1) \equiv M(t) \equiv M(t+1)$, Equation (1) gives a unique stationary solution $N_{i}(t) \equiv N_{i}(t+1)$ and $N(t) \equiv$ $N(t+1)$ (Song, 1982; Song et al., 1982). As we further drop the time dimenson, Equation (2) can be simplified and re-arranged as

$$
\begin{aligned}
E_{i} N_{i}= & {\left[\left(1-m_{i}\right)+\left(1-m_{i}\right)\left(1-m_{i+1}\right)+\cdots\right.} \\
& \left.+\left(1-m_{i}\right)\left(1-m_{i+1}\right) \cdots\left(1-m_{z-1}\right)\right] N_{i} .
\end{aligned}
$$

That is,

$$
\begin{aligned}
E_{i} & =\left(1-m_{i}\right)+\left(1-m_{i}\right)\left(1-m_{i+1}\right)+\cdots \\
& +\left(1-m_{i}\right)\left(1-m_{i+1}\right) \cdots\left(1-m_{z-1}\right) .
\end{aligned}
$$

Set $i=0$, we get the life expectancy at birth $E_{0}$ of the infant group $B$,

$$
\begin{gathered}
E_{0}=\left(1-m_{0}\right)\left[\left(1-m_{1}\right)+\left(1-m_{1}\right)\left(1-m_{2}\right)\right. \\
\left.+\cdots+\left(1-m_{1}\right)\left(1-m_{2}\right) \cdots\left(1-m_{z-1}\right)\right] .
\end{gathered}
$$

From here, one can see that infant mortality $m_{0}$ and under-five mortality $m_{0-4}$ have the biggest impact on $E_{0}$. When $m_{0}$ changes by $\Delta m_{0}$, we can make an approximate estimation:

$$
\Delta E_{0}=\frac{-E_{0}}{1-m_{0}} \Delta m_{0} \approx-\left(1+m_{0}\right) E_{0} \Delta m_{0}
$$

For example, when $E_{0}$ is around 75 , a decrease of $m_{0}$ (or $m_{0-4}$ ) by 10 per thousand would raise the life expectancy at birth $E_{0}$ by 0.78 years if $m_{0}$ is around 40 per thousand. Today, low infant and under-five mortality is the main reason for high $E_{0}$ in all developed countries.

Now denote the population density of age $i$ by $P_{\mathrm{i}}=\frac{N_{i}}{N}$. We here also drop the time dimension by assuming no changes in the total population and age-specific mortality rates over time. Obviously, $\sum_{i=0}^{z} P_{i}=1$. Since $b=B / N$ and $m$ are crude birth and death rates, from Equations (3) and (5) we can write

$$
\frac{E_{0} B}{N}=E_{0} b=\sum_{i=0}^{z}\left(1-m_{i}\right) P_{i}=\sum_{i=0}^{z} P_{i}-\sum_{i=0}^{z} m_{i} P_{i}=1-m,
$$

or abbreviated this as

$$
E_{0}=\frac{1-m}{b} .
$$

This implies that two of the three indicators $\left(m, b\right.$ and $\left.E_{0}\right)$ are interdependent.

Let $k_{i}(t) N_{i}(t)$ be the number of females reaching age $i$ in year $t$, and $k(t) N(t)$ be the total female population in year $t$. Suppose all women of age $i$ have borne $F_{i}(t)$ children in year $t$, so $f_{i}(t)=$ $\frac{F_{i}(t)}{k_{i}(t) N_{i}(t)}$ is the age-specific fertility rate per woman in year $t$. The sum of age-specific fertility rates, denoted by $T(t)$, is defined as the total fertility rate (TFR) in year $t$,

$$
T(t)=\sum_{i=a_{1}}^{a_{2}} f_{i}(t)
$$

where $a_{1}$ and $a_{2}$ are the lower and upper bounds of the childbearing age for females. Let $h_{i}(t)=\frac{f_{i}(t)}{T(t)}, \sum_{i=a_{1}}^{a_{2}} h_{i}(t)=1$, denote the women's reproductive age distribution. Census data from different countries have shown that $h_{i}(t)$ fits the gamma distribution in statistics (Song \& Yu, 1985). Thus the total number of infants borne by all women in the census year $t$ must 
be

$$
F(t)=T(t) \sum_{i=a_{1}}^{a_{2}} h_{i}(t) k_{i}(t) N_{i}(t) .
$$

Now suppose that all infants born this year, as denoted by $B(t)$, go through their lives at the same age-specific mortality rates $m_{i}(t)$ and give births to their own children according to the reproductive age distribution at the census year (i.e., no change in age-specific mortality rate over time), then $i$ year later, there are $N_{i}(t+i)$ among $B(t)$ would be able to survive and become a member of $N_{i}(t+i)$.

$$
N_{i}(t+i)=\left(1-m_{0}\right)\left(1-m_{1}\right) \cdots\left(1-m_{i-1}\right) B(t) .
$$

By putting $N_{i}(t+i) \equiv N_{i}(t)$ (or $\left.B(t) \equiv B(t+1)\right)$ and substituting the right-side value of $N_{i}$ into (10) after dropping the time dimension, we get

$$
F=T \sum_{i=a_{1}}^{a_{2}} h_{i} k_{i}\left(1-m_{0}\right)\left(1-m_{1}\right) \cdots\left(1-m_{i-1}\right) B .
$$

This means that, if $B$ infants go through their lives as all people do in the census year, they will have given births to $F$ children of their own. In this context, $F$ defined by (12) can be understood as the fertility level of the whole population in the census year. If $F=B$, the total number of $B$ 's children would be exactly the same as $B$ and just enough to replace $B$ in the future. In this special case, the total fertility rate (TFR), as denoted by $T_{r}$, is called replacement fertility (RLF). Hence, from (12), we have,

$$
T_{r}=\left[\sum_{i=a_{1}}^{a_{2}} h_{i} k_{i}\left(1-m_{0}\right)\left(1-m_{1}\right) \cdots\left(1-m_{i-1}\right)\right]^{-1} .
$$

It is evident that if total fertility rate $T$ is bigger than $T_{r}$, then $F>B$, meaning that the population is growing, and vice versa.

This implies that if a real population keeps $T=T_{r}$ for a long period of time and age-specific mortality rate stays unchanged or changes only slightly, then the population growth equation will approach a unique stationary solution of (1):

$$
\begin{aligned}
& N_{i}(t+1)=N_{i}(t), i=0,1, \cdots z, \\
& N_{0}(t+1)=N_{0}(t)=\text { const } .
\end{aligned}
$$

This also means that all of the population densities and the total population size are remaining constant over time, so long as the natural growth rate " $g$ " is zero, i.e., crude mortality rate $m$ and birth rate $b$ are equal. One can infer from (8) that in a zero-growth population the birth rate is just about inversely proportional to life expectancy $E_{0}$ at birth,

$$
b=\frac{1}{1+E_{0}}, B=N b=\frac{N}{1+E_{0}} .
$$

In other words, given the appropriate size of population $N$, in order to maintain a stationary population, the annual total births $B$ should be $N /\left(1+E_{0}\right)$.

Females are always in the focus of demography, since they take on the primary mission of reproduction. The family lineage of their children makes census data mostly reliable. The average number of daughters born per woman who survive beyond childbearing age is defined as net reproduction rate (NRR), denoted by $R_{\mathrm{n}}$.
In a stationary population, let $\overline{N_{i}}$ be the number of females in $N_{i}$, and $\bar{F}_{i}$ be the total number of girls born in $\bar{N}_{i}$ that year, $\bar{m}_{i}$ be female mortality in $\bar{N}_{i}$, and $\bar{h}_{i}$ be the daughter-bearing age distribution of women in $\bar{N}_{i}$. We then have

$$
\begin{aligned}
& R_{n}=T_{f}\left[\sum_{i=a_{1}}^{a_{2}}\left(1-\bar{m}_{0}\right)\left(1-\bar{m}_{1}\right) \cdots\left(1-\bar{m}_{i-1}\right) \bar{h}_{i}\right] \\
& T_{f}=\sum_{i=a_{1}}^{a_{2}} \frac{\bar{F}_{i}}{\bar{N}_{i}}, \bar{h}_{i}=\frac{\bar{F}_{i}}{\bar{N}_{i}} \cdot \frac{1}{T_{f}} .
\end{aligned}
$$

When $R_{n}=1$, every woman would have only one daughter able to survive the childbearing age in average to replace her mother. This total girl fertility rate, denoted by $T_{f}$, could be called net replacement reproduction rate (NRRR), denoted by $T_{f r}$.

$$
\begin{aligned}
T_{f r}= & {\left[\sum_{i=a_{1}}^{a_{2}}\left(1-\bar{m}_{0}\right)\left(1-\bar{m}_{1}\right) \cdots\left(1-\bar{m}_{i-1}\right) h_{i}\right] } \\
& \left(1-\bar{m}_{0}\right)\left(1-\bar{m}_{1}\right) \cdots\left(1-\bar{m}_{a_{1}-1}\right) .
\end{aligned}
$$

In order to see the relationship between common indicators $R_{n}, T_{r}$ and $T$, assume coarsely $k_{i}=\frac{1}{2}$ in (10)-(12), $m_{i}=\bar{m}_{i}, h_{i}$ $=\bar{h}_{i}, T_{f}=\frac{1}{2} T$. Then one gets an approximate relation from (15),

$$
\begin{aligned}
T_{r} & \approx\left(1-m_{0}\right)\left(1-m_{1}\right) \cdots\left(1-m_{i-1}\right) R_{n}^{-1} T \\
& \approx\left(1-\sum_{i=0}^{a_{1}-1} m_{i}\right) R_{n}^{-1} T .
\end{aligned}
$$

In the life table of the UNPD Database, only $R_{n}$ and $T$ are available. The value of replacement level of fertility (RLF) can be derived from (17) when needed. Table 1 shows some values of $T, R_{n}$ and $T_{r}$ of China and other selected countries in 1970s-1980s for comparison (Song \& Yu, 1981; UNPD, 2011).

\section{Age Distribution of a Zero-Growth Population}

In order to obtain the age composition of a zero-growth population with $E_{0}=80$, we assume its age-specific mortality rates to be the same as shown in Table 2, which is the estimated average for countries and areas like Japan, Iceland, Switzerland and Northern Europe with $E_{0}$ around 80 in 2005-2010 (UNPD, 2011). According to historical data of developed countries, when the life expectancy at birth, $E_{0}$, reached $75-80$ years, the infant and under-five mortality was reduced to 10 per thousand and lower.

Starting from (15) and (14), and taking $m_{i}$ from Table 2, we have, as shown in Column 1 of Table 3, worked out the composition of a zero-growth population known as "standard distribution". Note that the "standard" age distribution in a stationary population is irrelevant to a population size.

The results show that in a sophisticated society with zero population growth, 11 percent of the population are youths aged $15-24,59$ percent are working-age population aged $15-54$ who support 15 percent of children, and 25 percent are seniors aged 55 or older, which is similar to the state of affairs in most developed countries today. Also listed here for comparison are age distributions in China, developed countries, and the world 
Table 1.

Comparison of the replacement levels of fertility (RLF) in China and other selected countries.

\begin{tabular}{|c|c|c|c|c|}
\hline & Year & $\operatorname{TFR}(T)$ & $\operatorname{NRR}\left(R_{n}\right)$ & $\operatorname{RLF}\left(T_{r}\right)$ \\
\hline \multirow[t]{6}{*}{ China } & $1970-1975$ & 4.8 & 2.04 & 2.32 \\
\hline & $1975-1980$ & 2.9 & 1.28 & 2.27 \\
\hline & $1980-1985$ & 2.5 & 1.15 & 2.24 \\
\hline & $1995-2000$ & 1.8 & 0.78 & 2.24 \\
\hline & $2000-2005$ & 1.7 & 0.73 & 2.28 \\
\hline & $2005-2010$ & 1.6 & 0.71 & 2.29 \\
\hline \multirow[t]{4}{*}{ USA } & $1970-1975$ & 2.0 & 0.95 & 2.13 \\
\hline & $1975-1980$ & 1.8 & 0.85 & 2.12 \\
\hline & $2000-2005$ & 2.0 & 0.98 & 2.09 \\
\hline & $2005-2010$ & 2.1 & 1.00 & 2.09 \\
\hline \multirow[t]{4}{*}{ Japan } & 1970-1975 & 2.1 & 1.01 & 2.10 \\
\hline & $1975-1980$ & 1.8 & 0.88 & 2.09 \\
\hline & $2000-2005$ & 1.3 & 0.53 & 2.08 \\
\hline & $2005-2010$ & 1.3 & 0.54 & 2.08 \\
\hline \multirow[t]{4}{*}{ UK } & $1970-1975$ & 2.0 & 0.95 & 2.10 \\
\hline & 1975-1980 & 1.7 & 0.83 & 2.09 \\
\hline & $2000-2005$ & 1.7 & 0.80 & 2.09 \\
\hline & $2005-2010$ & 1.8 & 0.88 & 2.08 \\
\hline \multirow[t]{4}{*}{ France } & 1970-1975 & 2.3 & 1.09 & 2.11 \\
\hline & $1975-1980$ & 1.9 & 0.89 & 2.09 \\
\hline & $2000-2005$ & 1.9 & 0.91 & 2.09 \\
\hline & 2005-2010 & 2.0 & 0.95 & 2.08 \\
\hline \multirow[t]{4}{*}{ India } & $1970-1975$ & 5.3 & 1.87 & 2.78 \\
\hline & 1975-1980 & 4.9 & 1.83 & 2.54 \\
\hline & $2000-2005$ & 3.0 & 1.25 & 2.55 \\
\hline & $2005-2010$ & 2.7 & 1.17 & 2.50 \\
\hline \multirow[t]{4}{*}{ Bangladesh } & $1970-1975$ & 5.9 & 1.97 & 3.41 \\
\hline & $1975-1980$ & 5.5 & 2.35 & 2.79 \\
\hline & $2000-2005$ & 2.9 & 1.25 & 2.57 \\
\hline & 2005-2010 & 2.4 & 1.07 & 2.55 \\
\hline \multirow[t]{4}{*}{ Pakistan } & $1970-1975$ & 5.5 & 2.43 & 2.58 \\
\hline & $1975-1980$ & 5.5 & 2.53 & 2.59 \\
\hline & $2000-2005$ & 4.0 & 1.59 & 2.53 \\
\hline & 2005-2010 & 3.7 & 1.57 & 2.48 \\
\hline \multirow[t]{4}{*}{ Nigeria } & 1970-1975 & 5.5 & 2.08 & 3.12 \\
\hline & $1975-1980$ & 5.8 & 2.18 & 3.05 \\
\hline & $2000-2005$ & 5.8 & 1.98 & 3.01 \\
\hline & 2005-2010 & 5.5 & 2.00 & 3.00 \\
\hline
\end{tabular}

Note: author's calculation from Formula (13) using data from UNPD (2011).
Table 2.

Age-specific mortality rates in current developed countries with life expectancy at birth $80-85$ and Replacement Level of Fertility (RLF) around 2.1 .

\begin{tabular}{cccc}
\hline Age & $\mathrm{m}_{\mathrm{x}}(\%)$ & Lower $95 \%$ CI Bound & Upper $95 \%$ CI Bound \\
\hline 0 & 4.48 & 3.04 & 5.92 \\
$1-9$ & 0.17 & 0.13 & 0.20 \\
$10-19$ & 0.24 & 0.20 & 0.29 \\
$20-29$ & 0.52 & 0.43 & 0.52 \\
$30-39$ & 0.57 & 0.54 & 0.80 \\
$40-49$ & 1.53 & 1.25 & 1.80 \\
$50-59$ & 3.90 & 3.45 & 4.34 \\
$50-59$ & 9.85 & 9.39 & 10.34 \\
$70-79$ & 28.52 & 27.15 & 29.89 \\
$80-84$ & 54.91 & 51.85 & 57.97 \\
$85+$ & 151.59 & 148.18 & 157.47 \\
\hline
\end{tabular}

Note: CI: Confidence Interval. Source: author's calculation using data from UNPD (2011).

in 2010 and 2050 as projected by the UNPD (2011). It is assumed that China will stick to its low fertility policy $(\mathrm{TFR}=1.5$ - 1.6) till 2020 and gradually raise TFR to 1.8 in 2050. As a consequence, China's total population will peak out at 1.4 billion by 2030. Table 3 shows that, with a couple of exceptions, the age composition of China's population in the middle of the 21 st century will be more or less like that of some developed countries today and that of the zero-growth population with a similar life expectancy at birth. For example, according to the medium scenario of the world population prospects (UNPD, $2011)$, the proportion of senior citizens aged 55 or older $(25.7 \%)$ in China in 2050 will be slightly higher than that of Japan $(22.7 \%)$ today, but much lower than Japan $(35.5 \%)$ and South Korea $(32.8 \%)$ in 2050 . The total working-age population in China in 2050 is projected to be around 790 million. The proportion of working-age population in 2050 in China will be around $51 \%$, close to that of today's Japan (54\%), but higher than Japan (51\%) and South Korea (54\%) in 2050. The parent support ratio is an important indicator for measuring the burden of care that the middle-aged or young elders have to shoulder in taking care of their oldest-old parents, the ones among senior citizens who need care the most (Poston, 2008). The ratio is formulated with population aged 80 or older over those aged 50 - 54 in 2050. This ratio in China is also close to both that of Japan today and the standard population. Overall, the age structure of Chinese population is more or less similar to those of Western and Northern European countries in 2050. Figure 1 further reaches a similar conclusion in both low and high scenarios.

\section{Concluding Remarks}

We have presented a brief analysis of, and offered some insights into, the age composition of a zero-growth society with the connectedness between total fertility rate, net reproduction rate, and replacement level of fertility. As an illustration, a comparison is conducted between China's population distribution by age in the middle of this century with a stationary 
SONG J.

Table 3.

A comparison between a zero-growth population with $e_{0}=80$ - 85 and age distributions in China, developed regions and the World in selected years.

\begin{tabular}{|c|c|c|c|c|c|c|c|c|c|c|c|}
\hline & \multirow{2}{*}{$\begin{array}{l}\text { Standard age distribution } \\
\text { of zero-growth population }\end{array}$} & \multicolumn{2}{|c|}{ China } & \multicolumn{2}{|c|}{ Developed regions $^{*}$} & \multicolumn{2}{|c|}{ Japan } & \multicolumn{2}{|c|}{ Western \& Northern Europe } & \multicolumn{2}{|c|}{ The world } \\
\hline & & 2010 & 2050 & 2010 & 2050 & 2010 & 2050 & 2010 & 2050 & 2010 & 2050 \\
\hline Total population (billion) & $N$ & 1.34 & 1.30 & 1.23 & 1.31 & 0.127 & 0.109 & 0.029 & 0.031 & 5.90 & 9.31 \\
\hline$\%$ Children, aged 0 - 4 & 5.2 & 5.1 & 4.4 & 5.7 & 5.5 & 4.3 & 4.4 & 5.5 & 5.5 & 9.2 & 5.9 \\
\hline$\%$ Children, aged $5-14$ & 10.7 & 13.4 & 9.1 & 10.8 & 11.1 & 9.1 & 8.9 & 11.0 & 11.0 & 17.5 & 13.5 \\
\hline$\%$ Youth, aged $15-24$ & 11.0 & 15.8 & 9.5 & 12.8 & 11.0 & 10.0 & 9.1 & 12.5 & 11.1 & 17.5 & 13.5 \\
\hline $\begin{array}{l}\% \text { Primary school-age population, } \\
\text { aged } 5-11\end{array}$ & 5.4 & 7.8 & 5.4 & 5.4 & 5.7 & 5.4 & 5.4 & 5.5 & 5.5 & 10.5 & 8.2 \\
\hline $\begin{array}{l}\% \text { Secondary school-age population, } \\
\text { aged } 12-14\end{array}$ & 3.2 & 4.4 & 2.8 & 3.3 & 3.3 & 2.8 & 2.7 & 3.4 & 3.3 & 5.2 & 4.1 \\
\hline $\begin{array}{l}\% \text { High school-age population, } \\
\text { aged } 15-17\end{array}$ & 3.3 & 4.5 & 2.8 & 3.5 & 3.3 & 2.8 & 2.7 & 3.5 & 3.3 & 5.3 & 4.1 \\
\hline $\begin{array}{l}\% \text { University-age population, } \\
\text { aged } 18-24\end{array}$ & 8.5 & 12.2 & 5.8 & 9.3 & 7.7 & 7.2 & 5.4 & 9.0 & 7.8 & 12.3 & 9.4 \\
\hline $\begin{array}{l}\% \text { Women in reproductive ages, } \\
\text { aged } 15-49 \text { among total women }\end{array}$ & 39.4 & 55.4 & 35.2 & 45.4 & 38.4 & 41.5 & 32.3 & 45.7 & 38.5 & 52.1 & 44.9 \\
\hline $\begin{array}{l}\% \text { Working-age population, } \\
\text { aged } 15-59\end{array}$ & 52.8 & 58.2 & 52.5 & 51.7 & 51.5 & 55.2 & 45.2 & 50.0 & 51.5 & 52.2 & 57.7 \\
\hline$\%$ Working-age population, 15 - 54 & 58.7 & 72.4 & 51.0 & 57.5 & 57.5 & 54.0 & 51.1 & 55.1 & 57.5 & 55.5 & 53.3 \\
\hline$\%$ Population aged 50 or older & 31.3 & 12.3 & 33.9 & 21.7 & 31.9 & 30.5 & 41.5 & 23.4 & 31.9 & 11.0 & 21.8 \\
\hline$\%$ Population aged 55 or older & 25.4 & 8.2 & 25.5 & 15.9 & 25.7 & 22.7 & 35.5 & 17.4 & 25.9 & 7.5 & 15.2 \\
\hline$\%$ Population aged 80 or older & 9.5 & 1.4 & 7.5 & 4.3 & 9.4 & 5.3 & 14.5 & 4.8 & 10.3 & 1.5 & 4.3 \\
\hline Median age (years) & 44.5 & 34.5 & 48.7 & 39.7 & 44.3 & 44.7 & 52.3 & 40.9 & 44.4 & 29.2 & 37.9 \\
\hline $\begin{array}{l}\% \text { Population aged } 80 \text { or } \\
\text { older/population aged } 50-54\end{array}$ & 38.8 & 8.4 & 33.3 & 22.2 & 52.9 & 30.7 & 85.5 & 25.3 & 59.8 & 11.7 & 24.9 \\
\hline$\%$ Dependency ratio & 71.0 & 38.2 & 54.0 & 48.0 & 73.4 & 55.4 & 95.8 & 51.4 & 74.4 & 52.4 & 58.1 \\
\hline Life expectancy at birth (years) & $80-85$ & 73.2 & 79.4 & 77.5 & 83.0 & 83.2 & 87.7 & 79.7 & 84.7 & 58.5 & 75.9 \\
\hline
\end{tabular}

Note: *Developed regions comprise Europe, Northern America, Australia/New Zealand and Japan. Source: The 2010 World Population Prospects (UNPD, 2011).

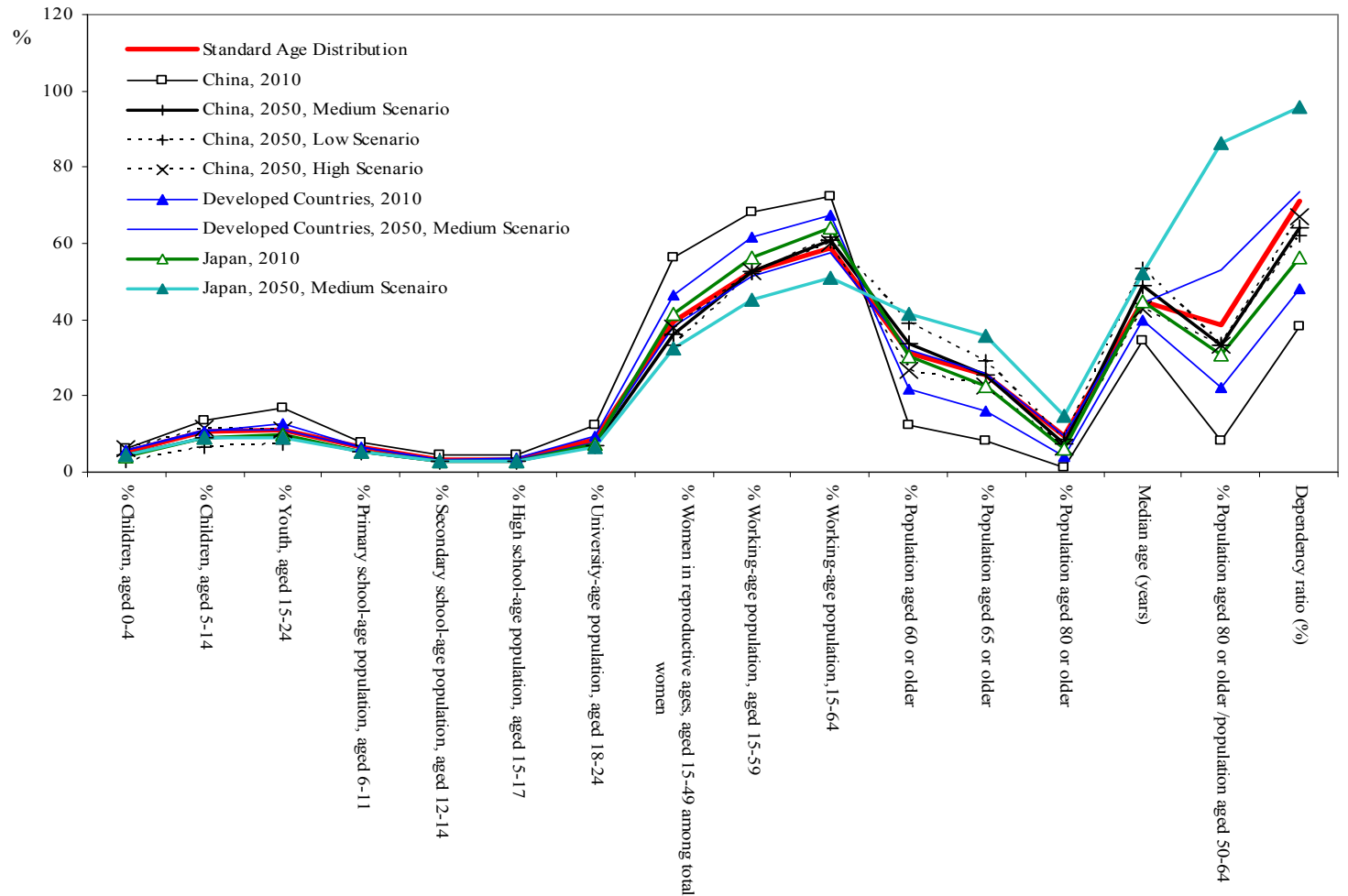

Figure 1.

A comparison between a zero-growth population with $e_{0}=80-85$ and age distributions in China, Japan and developed regions in selected years. Source: The 2010 World Population Prospects (UNPD, 2011). The high and low scenarios assume that total fertility rate will be, respectively, 0.5 more or 0.5 less than total fertility rate in the medium scenario. *Developed regions comprise Europe, Northern America, Australia/New Zealand and Japan. 
population and its corresponding demographic parameters in some developed countries. We have found that the age composition of China's population in 2050 will be close to that of some developed countries today, many of developed countries then; and it will also be close to the age composition of a stationary population if the fertility level follows its historical trend with linkage to the world's fertility evolution trajectory. This finding helps us better understand how the age structure changes from a non-stationary population today to a state close to a zero-population growth in the future.

Our results further demonstrate that the proportion of old adults aged 55 or older in the middle of the 21 st century is close to that of Japan today but lower than those of Japan and South Korea in 2050. Some researchers recently argued that the effects of changing age structure on economic growth mainly depend on support ratio, a ratio of the effective number of producers to the effective number of consumers (Lee \& Mason, 2011). Considering that 1 ) health condition of elderly population is improving ( $\mathrm{Gu}$ et al., 2009); 2) the postponement of retirement age has recently received increasing attention from both scholars and governments (Gu, 2000; Li, 2012; Zeng, 2007; Zhang, 2012); and 3) productivity would improve in the future, the actual support ratio in China in 2050 would expect to be higher than what some scholar has projected (Miller, 2011). Thus, we argue that the worries of "aging", a "senior boom", or a "winter of humanity" lack solid evidence. However, this does not mean that China does not need to pay attention to population aging. In the contrary, China needs to speed up her development of policies and facilities to meet elderly care needs, not only because of its sheer size, but also due to the rapid growth (Gu \& Vlosky, 2008; Zeng \& George, 2010). The roots of the rapid population aging in China do not simply lie in the current fertility policy, but in a combination of a low fertility rate, rising life expectancy, and the cumulative effect of past changes in birth and death rates (Banister, Bloom, \& Rosenberg, 2010). How large a population a country can support should be studied comprehensively and systematically by the scientific community and decided by legislative institutions that are well informed of political, economic, resource, and environmental backgrounds and technical factors (Cohen, 1995; Mahadevan et al., 1994; Qian, 1982). However, it is almost certain that having more people will put additional pressure on an already fragile environment (Banister, 1998; Edmonds, 1994; Niu \& Harris, 1995).

As Confucianism believes, health, longevity, wealth, benevolence, and natural death are the five great blessings for human being. It is the eternal pursuit of human societies to improve welfare and healthcare, to reduce mortality rates, and to extend longevity thereby. If everyone lives longer, the average age (median) and the proportion of elders and seniors will increase inevitably. Aging of people does not mean senescence of the whole society after all. A society will become more mature, more experienced, knowledgeable and intelligent (Ogawa, 2008). The youths can share their elders' accumulated knowledge and wisdom, and the old is keen to care the young. This has been the triumphant way of evolution of man and it should be a best frame for an ideal harmonious society in the future.

\section{REFERENCES}

Banister, J. (1998). Population, public health and the environment in
China. The China Quarterly, 155, 985-1015.

Banister, J., Bloom, D. E., \& Rosenberg, L. (2010). Population aging and economic growth in China. Program on the Global Demography of Aging Working Paper No. 53. Boston: Harvard University. http://www.hsph.harvard.edu/pgda/WorkingPapers/2010/PGDA_WP 53.pdf

Caí, F., \& Wang, M. (2005). Challenge facing China's economic growth in its aging but not affluent era. China \& World Economy, 14, 20-31. doi:10.1111/j.1749-124X.2006.00035.x

Cohen, J. E. (1995). How many people can the earth support? New York: Norton \& Co.

George, A. (2009). 7 billion and counting... New Scientist, 203, 23-24. doi:10.1016/S0262-4079(09)62564-1

$\mathrm{Gu}, \mathrm{D}$. \& Vlosly, D. A. (2008). Long-term care needs and related issues in China. In J. B. Garner, \& T. C. Christiansen (Eds.), Social sciences in health care and medicine (pp. 51-84). New York: Nova Publisher.

Gu, D. (2000). Thoughts on the redefinition of the old people. Chinese Journal of Population Science, 3, 42-51.

doi:10.1016/j.socscimed.2009.03.031

Gu, D., Dupre, M. E., Warner, D., \& Zeng, Y. (2009). Changing health status and health expectancies among older adults in China: Gender differences from 1992 to 2002. Social Science and Medicine, 58, 2170-2179.

Hussain, A. (2002). Demographic transition in China and its implications. World Development, 30, 1823-1834. doi:10.1016/S0305-750X(02)00070-0

Lee, R., \& Mason, A. (2011). Population aging and the generational economy: A global perspective (pp. 151-184). Northampton, MA: Edward Elgar Publishing, Inc.

Li, B. (2009). To overcome the greatest pass of the world. An interview with a Minister. Guang-Ming Daily, 15 September 2009 (In Chinese).

Li, J. (2012). Commission head seeks to raise retirement age. China Daily.

http://www.chinadailyapac.com/article/commission-head-seeks-raise -retirement-age

Mahadevan, K., Tuan, C.-H., Yu, J., Krishnan, P., \& Sumangala, M. (1994). Differential development and demographic dilemma: Perspectives from China and India. Delhi: B.R. Publishing Corporation.

Miller, T. (2011). The rise of the intergenerational state: Aging and development. In R. Lee \& A. Mason (Eds.), Population aging and the generational economy: A global perspective (pp. 151-184). Northampton, MA: Edward Elgar Publishing, Inc.

Niu, W.-Y., \& Harris, W. M. (1995). China: The forecast of its environmental situation in the 21 st century. Journal of Environmental Management, 47, 101-114. doi:10.1006/jema.1996.0039

Ogawa, N. (2008). The Japanese elderly as a social safety set. Asia-Pacific Population Journal, 23, 105-113.

www.unescap.org/esid/psis/population/journal/Articles/2008/V23N1 D1.pdf

Poston Jr., D. L., \& Zeng, Y. (2008). Introduction: Aging and aged dependency in China. In Y. Zeng, D. L. Poston Jr., D. Vlosky, \& D. Gu (Eds.), Healthy longevity in China: Demographic, socioeconomic, and psychological dimensions (pp. 1-18). Dordrecht: Springer Publisher.

Preston, S. H., Heuveline, P., \& Guillot, M. (2001). Demography: Measuring and modeling population processes. Oxford: Blackwell Publishers Ltd.

Qian, X. (1982). On system engineering. Beijing: Hunan Science and Technology Press (In Chinese).

Raftery, A. E., N. Li, H. Ševčíková, P. Gerland, \& Heilig, G. K. (2012). Bayesian probabilistic population projections for all countries. Proceedings of the National Academy of Sciences, 109, 13915-13921. doi:10.1073/pnas.1211452109

Ryder, N. (1975). Notes on stationary populations. Population Index, 41, 3-28. doi: $10.2307 / 2734140$

Song, J., \& Yu, J. (1985). Population control theory. New York: Springer-Verlag.

Song, J., \& Yu, J. (1991). Double-edged limit of total fertility rates. 
SONG J.

Science China Chemistry, 34, 1354-1361.

Song, J., (1982). Some developments in mathematical demography and their application to the People's Republic of China. Theoretical Population Biology, 22, 470-479.

Song, J., Yu, J., Wang, Y., Hu, S., Zhao, Z., Lia, J., Feng, D., \& Zhu, G. (1982). Spectral properties of population operators and asymptotic behaviour of population semigroup. Acta Mathematica Scientia, 2, 480-489.

United Nations Economic and Social Commission for Asia and the Pacific (ESCAP) (2009). Fifth APPC-Progress in implementation and contribution to development goals. Asia-Pacific Population Journal, 24, 1-228.

United Nations Population Division (UNPD) (2011). World population prospect 2010. New York: United Nations.

http://esa.un.org/unpd/wpp/index.htm

Wang, F. (2005). Can China afford to continue its one-child policy?
Asian Pacific Issues. No. 77. Honolulu, HI: East-West Center: www.eastwestcenter.org/fileadmin/stored/pdfs//api077.pdf

Zeng, Y. (2007). Options of fertility policy transition in China. Population and Development Review, 33, 215-245. doi:10.1111/j.1728-4457.2007.00168.x

Zeng, Y., \& George, L. (2010). Population ageing and old-age insurance in china. In D. Dannefer, \& C. Phillipson (Eds.), The SAGE handbook of social gerontology (pp. 420-430). London: SAGE Publications Ltd.

Zhang, J. (2012). Proposal to push retirement age to 55. China.org.cn http://www.china.org.cn/china/2012-07/02/content_25785258.htm

Zou, X., \& Yang, X. (2009). The long-term impact on the Chinese economy of an aging population. Social Sciences in China, 30, 197-208. doi:10.1080/02529200802704027 